\title{
Atuação da enfermagem na escola na perspectiva de professores da Educação Básica
}

DOI 10.26512/Ic.v24i0.18968

Neire Aparecida Machado Scarpini Centro Universitário Moura Lacerda

Wanderlei Abadio Oliveira Marta Angélica lossi Silva Luciane Sá de Andrade EMarlene Fagundes Carvalho Gonçalves Escola de Enfermagem de Ribeirão Preto, Universidade de São Paulo

\section{Resumo}

A atuação da enfermagem em escolas contribui para o desenvolvimento e a manutenção de hábitos de vida saudáveis dos escolares. Analisa-se as ações de promoção da saúde na escola sob a perspectiva do professor da educação básica. Trata-se de um estudo qualitativo. Participaram 28 professores de três escolas públicas de um município paulista, campos de estágio dos estudantes de enfermagem. Realizou-se 6 grupos focais. Os dados foram analisados seguindose a unidade de análise temática de Vigotski. As atividades foram consideradas como importantes na redefinição de hábitos de vida e modos de cuidado. A contribuição original do estudo reside: no exame de uma prática pouco explorada no campo da formação do enfermeiro no Brasil; na avaliação de outra categoria profissional do cenário prático sobre esse tipo de atuação.

Palavras-chave: Enfermagem. Educação Básica. Promoção da Saúde. 


\section{Performance of nursing in schools from the perspective of primary education teachers}

\section{Abstract}

Nursing practice at schools contributes for the development and maintenance of healthy life habits for students. This article analyzes health promotion practices in schools from the perspective of primary education teachers. A qualitative study, was conducted with 28 teachers from three public schools from a city in the state of São Paulo. These schools were internships sites for nursing students. Six focus groups were carried out. Data were analyzed according to Vigotski's thematic analysis. Activities were considered important in redefining life habits and methods of care. This study's original contributions are: the examination of a practice that receives little attention in the Brazilian nursing educational field and the assessment from another professional category of this type of practice.

Keywords: Nursing. Primary education. Health promotion.

\section{Actuación de enfermería en la escuela según visión de maestros de Educación Primaria}

\section{Resumen}

La actuación de enfermería en las escuelas contribuye al desarrollo y mantenimiento de hábitos de vida saludables en el alumnado. Se analizan acciones de promoción de salud en la escuela según el maestro de Educación Primaria. Estudio cualitativo. Participaron 28 maestros de tres escuelas públicas de un municipio paulista, campos de pasantía para los estudiantes de enfermería. Se organizaron 6 grupos focales. Datos analizados según la unidad de análisis temático de Vigotski. Las actividades fueron importantes para la redefinición de hábitos de vida y modos de cuidado. La contribución original del estudio reside: en el examen de una práctica poco explorada en el área de la formación del enfermero en Brasil, y en la evaluación de otra categoría profesional del escenario práctico sobre este tipo de actuaciones.

Palabras clave: Enfermería. Educación primaria. Promoción de la salud. 


\section{Letravail dessoinsinfirmiersàl'écolesousl'optique des professeurs de l'Enseignement de base}

\section{Résumé}

Le travail de soins infirmiers dans les écoles contribue au développement et à l'entretien de modes de vie sains des écoliers. Les actions de promotion de la santé à l'école sont analysées sous l'optique du professeur de l'enseignement de base. Ceci est une étude qualitative. Elle a été menée avec 28 professeurs de trois écoles publiques situées dans une commune de São Paulo, et qui sont des lieux de stage d'étudiants de soins infirmiers. Six groupes de réflexion ont été créés. Les données ont été analysées en suivant l'unité d'analyse thématique de Vigotski. Les activités ont été considérées comme importantes dans la redéfinition des modes de vie et des modes de soin. La contribution originale de l'étude concerne : l'analyse d'une démarche peu exploitée dans le domaine de la formation des infirmiers au Brésil ; l'évaluation d'une autre catégorie professionnelle dans un contexte pratique à propos de ce type de travail.

Mots-clés: Soins infirmiers. Enseignement de base. Promotion de la santé.

\section{Introdução}

A atuação do enfermeiro na saúde escolar realizando atividades educativas valoriza a profissão ao possibilitar a construção de um rol de conhecimentos sobre cuidado, prevenção e promoção direcionados para a atenção de crianças e adolescentes em idade escolar. Esse tipo de atuação, ainda, fortalece a articulação entre unidades básicas de saúde e escolas no tocante ao cuidado integral (Alvarenga, Silva, Silva \& Barbosa, 2012) e a consecução do artigo $3^{\circ}$, inciso II da Resolução CNE/CES n $n^{\circ} 3$ das Diretrizes Curriculares Nacionais do Curso de Graduação em Enfermagem (2001).

Em termos de mapeamento das problemáticas vivenciadas por estudantes brasileiros, a Pesquisa Nacional de Saúde do Escolar (PeNSE), em suas duas edições (2009 e 2012) demonstrou o envolvimento dos estudantes com tabagismo, consumo de álcool, práticas de alimentação inadequadas e sedentarismo, atividade sexual precoce, gravidez na adolescência e outros (Oliveira-Campos et al, 2014). Objetivamente, 
na edição de 2012, em uma amostra de 104109 escolares, 28,7\% afirmaram já ter feito sexo uma vez na vida, a maioria meninos. Os dados apontam que destes, 50,1\% ingeriram álcool e 64,5\% fizeram uso de drogas ilícitas. Apenas 38,9\% dos que já tiveram relação sexual usaram preservativo (Oliveira-Campos et al, 2014). Uma das respostas governamentais diante desse cenário é o Programa Saúde na Escola que, por meio de parcerias e da articulação entre profissionais da saúde e da educação, objetiva atender todo o território nacional e levar os escolares a aprenderem a fazer escolhas saudáveis e protagonizar a própria saúde (Malta et al, 2014).

De acordo com a literatura científica, a escola de educação básica tem sido reconhecida como espaço propício para o desenvolvimento de ações no nível da Atenção Básica em saúde e Enfermagem, por meio do desenvolvimento de projetos de extensão (Maciel et al, 2010) e estágios de prática dos graduandos que colocam diretamente o enfermeiro em formação neste espaço (Rache \& Santos, 2013). Além disso, existem relatos de experiências pedagógicas de educação em saúde e têm colaborado com a capacitação de professores (Souza, Munari, Souza, Esperidião \& Medeiros, 2010) e momentos de reflexão para os alunos especialmente ao envolver temas de sexualidade (Coelho \& Torres et al, 2012). Um estudo ao identificar a visão dos pais sobre a atuação de enfermeiros estudantes na escola de Educação Infantil revelou a valorização das ações de atividades educativas em saúde para as crianças, influenciando na qualidade de vida e em fatores que determinam a saúde (Alvarenga et al, 2012). Temas como sexualidade, gravidez na adolescência, métodos contraceptivos, DST, drogas, bullying, são pouco explorados na escola básica, podendo comprometer a saúde e o desenvolvimento de crianças e adolescentes em idade escolar e muito antes deles procurarem orientação na escola, buscam a unidade básica de saúde (Rache \& Santos, 2013; Coelho \& Torres et al, 2012). Esses temas podem ser abordados por enfermeiros na escola.

Nesse sentido, uma investigação buscou compreender o papel do enfermeiro no processo educativo em saúde na educação infantil no estado do Mato Grosso (Oliveira, 2013). A pesquisa revelou a necessidade de se integrar saberes da saúde e da educação na formação dos enfermeiros para garantir a união do cuidar e do educar na construção da promoção da saúde na escola e para romper com posturas higienistas rotineiramente compreendidas como do âmbito da enfermagem nas escolas (Oliveira, 2013). Outro estudo, que objetivou analisar a percepção de pais sobre ações educativas em saúde realizadas em uma escola por docentes e estudantes de enfermagem revelou que esse tipo de atuação resulta no estabelecimento de uma cultura de autocuidado e na adoção de hábitos saudáveis pelos estudantes, além de fortalecer outros tipos de atuação da enfermagem enquanto profissão. O papel do enfermeiro na escola pode somar ao dos atores escolares. Ações de promoção da saúde na escola ultrapassam a especificidade da assistência e atentam para atividades com temas de saúde a partir dos interesses dos escolares (Maia, Santos Jr., Fonseca, Silva \& Gonçalves, 2013). Pesquisa com enfermeiros mostra a importância dos estágios de promoção da saúde na escola de educação básica desenvolvendo atividades temáticas com os escolares, 
embora haja a preocupação porque essa atuação não está oficializada (Novaes \& Gonçalves, 2016).

Diante desse cenário, objetivou-se analisar as ações de promoção da saúde na escola desenvolvidas por licenciandos em enfermagem sob a perspectiva do professor da educação básica. Trata-se de uma abordagem histórico-cultural que foca o homem e suas relações com a sociedade e os significados sociais e particulares construídos na experiência real. Essa abordagem permite analisar e explicar os processos para conhecer por meio da linguagem as relações dinâmico-causais das interações dos sujeitos (Vigotski, 2014).

\section{Metodologia}

Trata-se de uma pesquisa qualitativa, de abordagem histórico-cultural, que utilizou a técnica de grupo focal em seis encontros para a construção dos dados. O contexto da pesquisa é composto por três escolas de educação básica: Escola do Jardim, Escola do Lago e Escola do Bosque - nomes fictícios. Nestas se concretiza uma parceria com a Escola de Enfermagem de Ribeirão Preto, Universidade de São Paulo, para os estágios de educação em saúde. Realizaram-se dois encontros de grupo focal em cada escola; um no início do segundo semestre de 2012 e um no final. Participaram desta pesquisa 28 professores, sendo 21 mulheres e 7 homens, com idades variando entre 22 e 60 anos. A maioria atuava na escola há mais de 3 anos. 0 critério de seleção dos participantes foi de acordo com a disponibilidade de tempo livre dos professores entre aulas no dia do encontro de coleta de dados.

$\mathrm{Na}$ coleta de dados foi utilizada a técnica de grupo focal (Gatti, 2012). No contato para agendamento do primeiro e segundo encontros do grupo focal, os participantes assinaram o Termo de Consentimento Livre e Esclarecido e preencheram um questionário de informações pessoais. Os encontros foram gravados e, posteriormente, transcritos. A identidade dos participantes foi preservada por meio da atribuição de nomes fictícios. Foram realizados dois encontros em cada escola em 2012. Para os encontros dos grupos focais foram utilizados os seguintes temas disparadores: a concepção de promoção da saúde; a inserção do licenciando em enfermagem na sala de aula; temas da saúde que emergem dos alunos no decorrer da aula e dificuldades de se trabalhar com algumas temáticas; expectativas sobre as ações de promoção da saúde na escola.

O referencial teórico-metodológico adotado pelo estudo foi a abordagem históricocultural de Vigotski, propondo-se entender os significados expressados na interação. A análise científica e objetiva do processo possibilita ver as relações dinâmico-causais do fenômeno, considerando os significados culturais construídos na interação dos 
homens (Vigotski, 2014). Ao final do processo de análise foram identificadas três unidades temáticas de análise: 1) a atuação da enfermagem nas escolas; 2) o trabalho de diferentes temáticas relacionadas à saúde e ao cuidado; e 3) saúde na escola como uma tarefa complexa e difícil.

Esta pesquisa atende aos critérios éticos do Conselho Nacional da Saúde, da Resolução 196/96 e teve a aprovação conforme Parecer n 95.038.

\section{A atuação da enfermagem nas escolas}

Nesta primeira unidade temática, apresenta-se são apresentados os significados atribuídos pelos professores que apontam o modo como veem as ações de promoção da saúde e como ocorre esse processo na escola com destaque à organização didática e implementação das atividades desenvolvidas pelos estagiários de licenciatura em enfermagem na escola:

É, bem planejado. Elas não vêm aqui para falar... elas vêm aqui com a teoria e com a prática... porque teoria e prática são coisas, assim, importantes né? A prática é superimportante para que eles aprendam mesmo a ter a boa educação, boa saúde, né?É o cidadão do futuro, do futuro do país. (Roberto, primeiro encontro, Escola do Bosque).

Os alunos estão se mostrando bem interessados... o que eu percebi no sexto ano... eles vão... eles querem participar... está sendo bem interessante! (Pâmela, primeiro encontro, Escola do Bosque).

A dedicação delas. A gente vê que elas são muito dedicadas...todos os dias elas vêm... trazem sempre materiais novos, atualizados para eles. (Jussara, primeiro encontro, Escola do Bosque).

Os significados construídos nestas falas demonstram o envolvimento dos alunos nas atividades e o interesse pelas aulas dos enfermeiros licenciandos. Os professores destacaram ainda suas dificuldades diante de alguns temas, trabalhados com naturalidade pelos acadêmicos de enfermagem:

A gente sabe da nossa função na escola, mas a gente acaba falhando nesse detalhe, de falar sobre a higiene. Sobretudo, eu, professora de História, às vezes falo, mas não tenho aquele hábito de falar, de trabalhar com isso, de separar um momento e trabalhar com isso. Então essa presença dos enfermeiros aqui auxilia bastante nisso, porque é um momento da ciência para a gente falar daquilo (Renata, primeiro encontro, Escola do Lago). 
Como a gente tem um convívio um pouco maior com eles, eles não se sentem muito à vontade. Existe um perigo também: se a gente for falar de sexualidade ou alguma coisa relacionada com isso, a gente pode ser confundida por eles, e se tornar um problema muito maior. A gente falou da última reunião, pelo fato de eu ser homem, fica muito difícil abordar essa situação numa sala. [...]. Então, o fato deles (os enfermeiros) estarem fora da escola, vindo de um ambiente diferente, eu acho que os alunos se sentem um pouco mais à vontade com eles, porque eles tornam-se imparciais. (Claudemir, segundo encontro, Escola do Lago).

Os significados expressados sobre as dificuldades dos professores na abordagem de temas e ações de promoção da saúde na escola ora são justificados pela área de atuação, ora é o contato diário com o aluno que vem a ser um fator impeditivo no trato de questões de saúde como higiene e sexualidade.

\section{O trabalho de diferentes temáticas relacionadas à saúde e ao cuidado}

Esta unidade temática evidencia a importância atribuída aos temas desenvolvidos a partir da realidade dos alunos da educação básica.

O pessoal da enfermagem está passando tudo para eles. Sobre higiene corporal é importantíssimo passar para eles. Agora sobre sexo e droga é fundamental conversar com eles a partir do sexto ano. A gente tem meninas de treze anos grávidas. Estava uma epidemia de criança grávida aqui (Mara, primeiro encontro, Escola do Lago)

O que eu percebo na sala de aula, quando fala de sexualidade, mas ao contrário daquilo que a gente imagina, eles não têm todo o conhecimento que deveriam ter para começar a prática sexual. (Renata, primeiro encontro, Escola do Lago).

Acho que a questão da sexualidade aqui é uma característica diferenciada. Falo pela própria região em que está localizada a escola. (Luan, primeiro encontro, Escola do Lago).

São profissionais da área. (Virgínia, segundo encontro, Escola do Lago).

As professoras Mara e Renata identificam na interação com os alunos temas que fazem parte do cotidiano nos quais os mesmos não possuem o conhecimento adequado para o autocuidado do corpo.

Outros temas apareceram, e foram relacionados às atividades curriculares desenvolvidas em aulas, como se observa nas falas apresentadas a seguir: 
Como as enfermeiras estavam falando sobre alimentação e no oitavo ano, o caderninho do aluno do terceiro bimestre tem esse tema de alimentação. Então, já estava havendo o trabalho com as enfermeiras e veio, coincidiu com Inglês, a gente, então, trabalhou bastante em relação a vocabulário. (Priscila, segundo encontro, Escola do Bosque).

Vocabulário! E eles ficaram atentos sobre o que não era. Essa alimentação, esse fast food, as comidas rápidas. Então eles: " - Nossa, professora! Então é? Faz mal? Não é legal alimentar assim?". "- Não, não é!" - E a enfermeira falando, nossa, eles ficaram super-interessados. (Luana, segundo encontro, Escola do Bosque).

Eles se comunicam mais entre eles. O caso igual o do bullying que eu falei, que eu achei legal. O bullying na internet. Eu achei legal porque eles colocaram dentro do balão o apelido que eles não gostavam, e eles não sabiam. Tinha alunos que não sabiam que não gostavam, porque dava até briga. Depois disso, eles começaram a parar com isso e eu vi que eles ficaram mais próximos um do outro, depois de ele falar assim: - não, eu não gosto desse apelido. (Maísa, segundo encontro, Escola do Bosque).

Também foi destacada nesta unidade a questão do bullying pela internet, explorado pelos enfermeiros licenciandos por meio de uma dinâmica que levou os alunos a se depararem com apelidos criados entre os mesmos. No decorrer da atividade, ressignificar os apelidos levou os alunos a rejeitarem tal prática. A interação com os alunos levou os professores a construírem as suas representações e se posicionarem a respeito das práticas promoção da saúde e os seus desdobramentos na escola.

\section{Saúde na escola como uma tarefa complexa e difícil}

Identificou-se nesta unidade temática que professores buscam explicações e justificativas ressignificando saúde como uma ação complexa.

Violência, drogas. Drogas hoje em dia é uma questão de saúde. A gente vê em cada caso que passa nas redes de televisão que o negócio está violento. A pessoa é jogada na rua por causa de droga. A pessoa deixa de se cuidar, para de viver, tudo por causa do vício. O vício é uma doença, então, está na área de saúde. (Antônia, primeiro encontro, Escola do Bosque).

Todo seu meio, eu acredito. O meio cultural tudo interfere. Obviamente, dependendo da classe social da pessoa, a pessoa tem algo mais a favor ou contra. Então, todo o meio envolve a saúde, no geral. Às vezes tem dado implícito, mas a gente não vê. Tudo envolve. Porque tudo vai girar em torno do seu corpo. Você às vezes tem um estado de stress, um exemplo, ele vai gerar em torno do seu corpo. (Maísa, primeiro encontro, Escola do Bosque). 
Para a professora Antônia o significado de saúde envolve determinantes sociais responsáveis pela falta de saúde, distantes da qualidade de vida, cuja ênfase discorre sobre a consequência das drogas e violência sobre as condições de saúde. A fala da professora Maísa sugere a culpabilização do indivíduo, e do seu meio cultural e social como responsável pelas condições de vida.

Assim a professora Luciana referiu-se às enfermeiras licenciandas que atuavam na Escola do Jardim:

Elas são profissionais de saúde. É o contrário de um historiador, um geógrafo. Ela que é a professora de Matemática abordar o assunto, os pais impõem muito resistência e distorcem aquilo que nós estamos falando, que é dar uma informação e acaba mal interpretado. Eu acho que se tiver isso já no planejamento e isso estiver engajado, entrosado de uma forma multidisciplinar, seria muito mais fácil. (Luciana, primeiro encontro, Escola do Jardim).

Entende-se nessa fala a educação em saúde como responsabilidade do profissional de saúde. Discorrer sobre temas de saúde pode ter possibilitado ressignificações de situações vivenciadas na escola. O seu posicionamento é permeado de sentido sobre como esta professora percebe a posição dos pais em se tratando de questões de saúde.

Ao se dirigirem aos seus alunos, os professores se reportam às condições de vida como impasses que repercutem no dia a dia da escola.

Nós temos aluno aí que tem dezesseis pessoas na casa, moram todos juntos, no mesmo cômodo. Então ali é tudo! Ali é o quarto de todos, ali é cozinha. Você imagina o que é? A realidade deles é essa. (Mara, primeiro encontro, Escola do Lago).

Como trabalhar isso? Trazer algo da universidade para nos ajudar em relação a essa sexualidade, em relação a essa droga que eles costumam vivenciar no dia-a-dia, mas não usam. Talvez um irmão, não sei. Então como trabalhar com a criança, já que não tem como tirar a criança desse meio? Como trabalhar a formação dessas crianças em relação a isso? (Luan, primeiro encontro, Escola do Lago).

A primeira unidade temática "a atuação da enfermagem nas escolas" mostra o significado atribuído às práticas de promoção da saúde realizadas na escola como parte do processo de formação. Por trás da formação dos graduandos em bacharelado e licenciatura em enfermagem existe uma intencionalidade que prima pelos conhecimentos organizados e planejados com base no currículo integrado capaz de articular ensino e teoria com a prática de forma dinâmica e ativa (Gonçalves, Santos, Silva \& Andrade, 2014). Por meio da mediação os conhecimentos implícitos à promoção da saúde são traduzidos didaticamente em conhecimento escolar para os alunos da escola básica. Desde o início do curso de graduação há a articulação com as teorias 
da educação e a visão humanizadora de acolhimento do outro em sua singularidade (Fortuna, Gonçalves, Silva \& Santos, 2012). Destaca-se nas falas dos professores, a valorização da prática desenvolvida pelos enfermeiros licenciandos com base na articulação teoria e prática, no planejamento das atividades, no cronograma, abertura para a participação dos professores nas atividades, nos materiais didáticos trazidos e produzidos pelos mesmos, na qual ocorre que a metodologia dialética (Gonçalves et al, 2014; Fortuna et al, 2012), ao subsidiar essas práticas fundamenta também os fenômenos escolares. Outro ponto destacado nesta unidade temática, de acordo com os professores Renata e Claudemir, é o fato do convívio diário dificultar os alunos a expressarem as suas dúvidas pessoais sobre questões de saúde. Outro fator apontado foi o professor da área de História não sentir-se à vontade para discorrer sobre questões de saúde e acabar elegendo frequentemente a disciplina de Ciências, "local estabelecido para a educação sexual", de predominância biológica para tratar assuntos especialmente sobre sexualidade (Souza et al, 2010). Estudo mostra que professores têm pouco domínio sobre conhecimentos de saúde (Ferraro, 2011).

Esta fala destaca a preocupação dos pais não entenderem bem caso os professores abordem em sala de aula assuntos de sexualidade. Para os professores, podem ocorrer equívocos e distorções por parte dos familiares, caso o professor tente lidar com esses assuntos. Com isso, esses professores entendem o enfermeiro licenciando com capacidade para lidar com questões de saúde voltadas para a sexualidade. Desse modo, e a partir da ideia de Foucault, a questão da sexualidade vem sendo referendada mais como dispositivo histórico e cultural, abarcando o sexo como significação de controle sobre o prazer. Assim, nos currículos das escolas existe um mecanismo sobre esse tema por meio de estratégias pedagógicas que fiscalizam, dotam regras e até medicalizam os padrões de comportamento entendidos como fora do "normal" (Barros, 2013). Para a realização das ações de promoção da saúde na escola, primeiro é relevante que os enfermeiros compreendam como essa questão é tratada nas escolas para saber como devem ser desenvolvidas suas atividades com os alunos (NOVAES \& GONÇALVES, 2016).

A segunda unidade temática "o trabalho de diferentes temáticas relacionadas à saúde e ao cuidado", aponta os temas desenvolvidos nas ações de promoção da saúde, evidenciando-se os seguintes: higiene corporal, drogas, gravidez na adolescência, sexualidade, métodos contraceptivos, doenças sexualmente transmissíveis, alimentação saudável, bullying. Embora esses temas tenham sido sugeridos pelos alunos das escolas que recebem os enfermeiros licenciandos para o estágio, tais temas fazem parte das ações de promoção da saúde do Programa Saúde na Escola.

Evidenciou-se a preocupação dos professores em torno da saúde sexual dos adolescentes. Estudo identificou que 30,7\% do total de 191 mulheres adolescentes ficaram grávidas sem planejamento. Essas adolescentes enquadradas com baixa escolaridade, pertencem a famílias de baixa renda, com elevada vulnerabilidade 
social e econômica (Coelho \& Andrade et al, 2012). Talvez essa pesquisa apresentada possa confirmar a visão dos professores sobre o grande número de adolescentes grávidas, o início da vida sexual precoce, a sexualidade estar imbricada à região da escola e a importância de se desenvolver temas sobre sexualidade. Esses significados contemplados pelos professores podem ter relação com os assuntos de saúde desenvolvidos no currículo escolar, no entanto, podem não ter relação com a própria realidade na qual a escola está inserida. A distância entre o conhecimento ensinado nas escolas e as necessidades dos alunos pode repercutir em dificuldades de aprendizagem, implicando diretamente na saúde dos escolares. Por outro lado, enfermeiros são valorizados e reconhecidos em suas atuações na escola. Conhecimentos de promoção e prevenção da saúde ao atingirem os pais acabam repercutindo positivamente no lar e na qualidade de vida dos seus integrantes (Alvarenga et al, 2012).

Para os professores, as atividades de educação em saúde acabam sendo integradas ao currículo da escola e os desdobramentos das ações reconhecidos nas aulas de outros professores. Temas como alimentação saudável tem sido foco de pesquisas e apontam os benefícios levados às escolas4. O tema alimentação faz parte do Caderno do Aluno que faz parte da Proposta Curricular do Estado de São Paulo de 2009 (Neira, 2011). A metodologia utilizada para as atividades de educação em saúde pelos enfermeiros licenciandos na escola básica denotam o caráter apresentado nessas abordagens e se destacam como um trabalho interdisciplinar.

O bullying foi destacado como sinônimo de humilhação por meio de estereótipos e apelidos. No Brasil, cerca de 7,2\% dos escolares que participaram da amostra da PeNSE de 2012 afirmaram ter sofrido bullying. Frequentemente, insultos são as mais frequentes formas de bullying para as vítimas (Silva, Pereira, Mendonça, Nunes \& Oliveira, 2013). Esse é um tema relevante para a área da saúde, pois trata-se de um fenômeno reconhecido internacional e nacionalmente como problema de saúde pública.

A terceira e última unidade temática aborda "saúde na escola como uma tarefa complexa e difícil" na compreensão dos professores. A professora Antônia relaciona saúde ao problema social causado pelo fenômeno da drogadição e da violência ligando falta de saúde a fatores sociais.

Outro ponto destacado nesta unidade temática é a interferência do meio cultural. Para Vigotski (2014), o homem é um ser social, histórico e cultural e os instrumentos mediadores que contribuem para a sua constituição ontológica configuram o seu modo de ver o mundo, considerando o seu lugar no âmbito da cultura. Cabe considerar o processo histórico do discurso higienista de que tudo envolvendo saúde gira em torno do corpo humano e das condições de vida das pessoas. No entanto, a literatura mostra que também os fatores econômicos e políticos implicam na constituição de pessoas saudáveis ou não. Indo no sentido inverso de que saúde está relacionada à droga, o Programa Saúde na Escola - PSE (Casemiro, Fonseca \& Secco, 2014) ao 
enfatizar ações de educação em saúde para a promoção da saúde, visa colaborar com o empoderamento das pessoas para que construam meios de controle sobre suas vidas, ou seja, como ferramenta a ser utilizada para promover a própria saúde.

Os professores reconhecem as ações de promoção da saúde desenvolvidas pelos enfermeiros em formação, há unanimidade de que eles possuem as bases essenciais para tal responsabilidade. Os enfermeiros licenciandos em suas práticas pedagógicas e estratégias didáticas trazem o propósito de produzir mudanças no modo de organização do trabalho com a saúde, dentro de uma educação transdisciplinar (Gonçalves et al, 2014). Os significados trazidos pelos professores confirmam o papel do profissional da saúde dentro da escola. Houve unanimidade sobre a inserção das atividades de saúde desenvolvidas por profissionais da saúde, no planejamento, como parte integrante do currículo com foco nos conteúdos para a promoção da saúde.

A análise revela que os professores veem como importante o papel dos enfermeiros licenciandos em relação ao ponto de vista dos pais, ao lidar com determinados assuntos e temas, ajudando-os a lidar com a realidade que o aluno traz para o cotidiano da escola. Essa postura pode ser resultante do processo formativo e da possibilidade de apropriação teórica dos enfermeiros frente às ações promotoras de saúde nos momentos de interação no campo da prática, com base nos princípios da Carta de Ottawa articulada à educação em saúde; a partir da prática dialógica na busca da emancipação e empoderamento dos sujeitos e na consideração da cultura que singulariza cada um com o reflexo da sociedade na qual faz parte.

\section{Considerações finais}

Oestudo revelouque os professores estão interessados eidentificam a pertinência das intervenções de educação em saúde junto aos seus alunos e desenvolvidas por profissionais da enfermagem nas escolas. Para os professores, as intervenções educativas realizadas pelos enfermeiros licenciandos são capazes de envolver os alunos e podem ser transformadas em práticas de cuidado com a saúde no cotidiano, auxiliando no processo formativo dos mesmos.

Este estudo limita-se em não identificar as necessidades de educação em saúde para a promoção da saúde dos próprios professores, uma vez que o ambiente de trabalho implica em baixa valorização profissional, sobrecarga, exaustão, conflitos de diferentes ordens e no relacionamento com os alunos e reflete na vida profissional e pessoal, repercutindo diretamente na qualidade de vida. Outros estudos são encorajados nessa direção.

Concebe-se a enfermagem na escola uma prática ainda pouco reconhecida. Neste 
sentido, este estudo contribui para o exame de uma prática pouco explorada no campo da formação do enfermeiro no Brasil e na avaliação de outra categoria profissional do cenário prático sobre esse tipo de atuação da Enfermagem.

\section{Referências}

Alvarenga, W. A., Silva, M.E.D.C., Silva, S. S., Barbosa, L. D. C. S. (2012). Ações de educação em saúde realizadas por enfermeiros na escola: a percepção dos pais. Revista Mineira de Enfermagem, 16(4), 522-527.

Barros, J. P. P. (2013). Biopolítica e educação: relações a partir das discursividades sobre saúde na escola. Educação \& Realidade, 38(1), 361-381.

Casemiro, J. P., Fonseca, A. B. C., Secco, F. V. M. (2014). Promover saúde na escola: reflexões a partir de uma revisão sobre saúde escolar na América Latina. Ciência e Saúde Coletiva, 19(3), 829-840.

Coelho, E. A. C., Andrade, M. L. S., Vitoriano, L. V. T., Souza, J. J., Silva, D. O., Gusmão, M. E. N., Nascimento, E. R., Almeida, M. S. (2012). Associação entre gravidez não planejada e o contexto socioeconômico de mulheres em área da Estratégia Saúde da Família. Acta Paulista de Enfermagem, 25 (3), 415-422.

Coelho, M. M. F., Torres, R. A. M., Miranda, K. C. L., Cabral, R. L., Almeida, L. K. G. \& Queiroz, M. V. O. (2012). Educação em Saúde com Adolescentes: compartilhando vivências e reflexões. Ciência, Cuidado e Saúde, 11(2), 390-395.

Ferraro, M. R. M. (2011). A concepção de professores sobre saúde na escola. Dissertação Mestrado. Ribeirão Preto: Faculdade de Medicina de Ribeirão Preto, Ribeirão Preto, SP.

Fortuna, C. M., Gonçalves, M. F. C., Silva, M. A. I., Santos, R. A. (2012). A produção de narrativas crítico-reflexivas nos portfólios de estudantes de enfermagem. Revista Escola de Enfermagem da USP, 46(2), 452-459.

Gonçalves, M. F. C., Santos, R. A., Silva, M. A. I., Andrade, L. S. (2014). ExperienceBased Learning in Nursing Teacher Education: A Historical-Cultural Research Study. American Journal of Educational Research, 2(5):316-324.

Gatti, B. A. (2012). Grupo focal na pesquisa em Ciências Sociais e Humanas. Brasília: Liber. 
Maciel, E. L. N., Oliveira, C. B., Frechiani, J. M., Sales, C. M. M., Brotto, L. D. A., Araújo, M. D. (2010). Projeto Aprendendo Saúde na Escola: a experiência de repercussões positivas na qualidade de vida e determinantes da saúde de membros de uma comunidade escolar em Vitória, Espírito Santo. Ciência e Saúde Coletiva, 15(2), 389-396.

Maia, L. S., Santos Jr, E. A., Fonseca, T. K., Silva, M. A. I., Gonçalves, M. F. C. (2013). Atividades educativas em saúde na educação básica: um estudo a partir da inserção de estudantes de licenciatura em enfermagem na escola. Revista Ibero-Americana de Estudos em Educação, 8(3), 662-666.

Malta, D. C., Silva, M. M. A., Albuquerque, G. M., Lima, C. M., Cavalcante, T., Jaime, P. C., Silva Jr., J. B. (2014). A implementação das prioridades da Política Nacional de Promoção da Saúde, um balanço, 2006 a 2014. Ciência e Saúde Coletiva, 19(11), 4301-12.

Neira, M. G. A. (2011). Proposta Curricular do Estado de São Paulo na perspectiva dos saberes docentes. Revista Brasileira de Educação Física e Esporte, 25: 23-27

Novaes, C. B., Gonçalves, M. F. C. (2016). Promoção da saúde na educação básica: possibilidades e desafios para a licenciatura em enfermagem. In: Gonçalves, M. F. C., Andrade, L. S., Silva, M. A. I. Promoção da Saúde na Educação Básica e a Licenciatura em Enfermagem. São Paulo: Iglu, 74-95.

Oliveira-Campos, M., Nunes, ML, Madeira, F. C., Santos, M. G., Bregmann, S. R., Malta, D. C. Giatti, L., Barreto, S. M. (2014). Comportamento sexual em adolescentes brasileiros, Pesquisa Nacional de Saúde do Escolar (PeNSE 2012). Revista Brasileira Epidemiologia, 25(17), 116-130.

Oliveira, P. R. (2013). O papel do enfermeiro no processo educativo em saúde na educação infantil: concepções de educadores e enfermeiros. Dissertação de Mestrado. Cuiabá: Universidade Federal de Mato Grosso, Cuiabá, MT, Brasil.

Rasche, A. S. \& Santos, M. S. S. (2013). Enfermagem Escolar e sua Especialização: uma nova ou antiga atividade. Revista Brasileira de Enfermagem, 66(4), 607-610.

Resolução CNE/CES n ${ }^{\circ}$ 3, de 7 dezembro 2001. Institui as Diretrizes Curriculares Nacionais do Curso de Graduação em Enfermagem. Conselho Nacional de Educação, Câmara de Educação Superior. Brasília, DF. Recuperado em 1 dezembro 2017, de portal.mec.gov.br/cne/arquivos/pdf/CES03.pdf 
Souza, M. M., Munari, D. B., Souza, S. M. B., Esperidião, E. \& Medeiros, M. (2010). Qualificação de Professores do Ensino Básico para Educação Sexual por meio da Pesquisa-Ação. Ciência, Cuidado e Saúde, 9(1), 91-98.

Vigotski, L. S. (2014). A formação social da mente. São Paulo: Martins Fontes.

Silva, M. A. I., Pereira, B., Mendonca, D., Nunes, B., Oliveira, W. A. (2013). The involvement of girls and boys with bullying: an analysis of gender differences. International Journal of Environmental Research and Public Health, 10(12), 68206831.

Neire Aparecida Machado Scarpini é Professor Doutor, Centro Universitário Moura Lacerda, PPGE - Pedagoga, doutorado pela Escola de Enfermagem de Ribeirão Preto, USP. Pesquisa financiada pela Capes - Projeto Pró-Ensino na Saúde 2037/2010 - A formação de professores no contexto do SUS: políticas, ações e construção de conhecimento.

Wanderlei Abadio Oliveira é Psicólogo, doutorado pela Escola de Enfermagem de Ribeirão Preto, Universidade de São Paulo, Centro Colaborador da OMS para o Desenvolvimento da Pesquisa em Enfermagem, Ribeirão Preto, SP, Brasil.

Marta Angélica lossi Silva é PhD, Professor Associado, Escola de Enfermagem de Ribeirão Preto, Universidade de São Paulo, Centro Colaborador da OMS para o Desenvolvimento da Pesquisa em Enfermagem, Ribeirão Preto, SP, Brasil.

Luciane Sá de Andrade é PhD, Professor Doutor, Escola de Enfermagem de Ribeirão Preto, Universidade de São Paulo. Centro Colaborador da OPAS/OMS para o desenvolvimento da pesquisa em enfermagem, Ribeirão Preto, SP, Brasil.

Marlene Fagundes Carvalho Gonçalves é PhD, Professor Associado, Escola de Enfermagem de Ribeirão Preto, Universidade de São Paulo, Centro Colaborador da OPAS/OMS para o desenvolvimento da pesquisa em enfermagem, Ribeirão Preto, SP, Brasil. 